\title{
Research on brand Positioning Validity in Xiaomi enterprise Management
}

\author{
Lu Zhiwei ${ }^{1}$ \\ ${ }^{1}$ School of Business Administration, Zhejiang Gongshang University, Hangzhou, Zhejiang, China
}

\begin{abstract}
With the development of market economy, fierce competition has penetrated into every aspect of the society. In the past, Chinese companies have gained a large market share by relying on the price advantage of low-priced products. However, in recent years, labor costs have been rising, environmental damage has become more serious, and independent innovation is very important in enterprise management. All these mean that what is important now is not to find ways to reduce the cost of products, but to find ways to optimize enterprise management strategy. Therefore, in the process of enterprise management, brand positioning is particularly important. First of all, on the basis of literature research, this paper puts forward two brand positioning measurement indexes, namely consistency and brand positioning performance: consistency is mainly used to test the expectations of the enterprise design image and it fits the customer image, and brand performance is mainly from the customer perspective to examine the effects of brand positioning, or used to measure the consumers' brand loyalty. Secondly, this paper selects Xiaomi as a case for empirical study, and conducts questionnaire distribution and data collection and analysis based on the case of xiaomi's enterprise management. Finally, this paper uses SPSS software to analyze the data collected to verify the consistency of brand positioning and brand positioning performance of Xiaomi in enterprise management, and also to verify the positive correlation between the two. The investigation of this paper finally confirms the validity of brand positioning of Xiaomi's enterprise management process, and also shows that the designed indicators are reasonable.
\end{abstract}

\section{THE INTRODUCTION}

\subsection{The background of the topic and the questions raised}

\subsubsection{The background of the topic}

Brand is consumers' understanding and association of the brand, which exists in the minds of consumers. Brand positioning is the process in which an enterprise creates an expected brand image and transmits it to the minds of consumers, so as to distinguish the brand from the rival brand, or to connect the brand with the unique needs of consumers. Therefore, brand positioning should be regarded as an important task of marketing strategy.

With the development of market economy, fierce competition has penetrated into every aspect of the society. Chinese companies have come a long way thanks to the price advantage of cheap products, but rising Labour costs, environmental problems and the need for innovation all mean the old path is no longer feasible and products must be better marketed. Therefore, under the current environmental background, brand positioning is more important for the company. If the enterprise does not handle the brand positioning properly, it will not only cause the loss of customers, but also seriously waste the resources of the enterprise, and even cause the enterprise to fail in the competition. The research of this paper is based on such a realistic foundation as the starting point and the end point.

\subsection{2 the questions raised}

There are three main problems in the process of brand positioning: first, brand positioning awareness is still lacking. Some enterprises' brand positioning awareness has not kept pace with The Times. In today's era, they still adopt relatively backward brand positioning awareness and do not have innovative ideas, so that marketing cannot play a role in enterprise management. Second, the brand positioning planning in the early stage is insufficient. Some enterprises in brand positioning planning activities, in the early stage did not do a full preparation work, blindly pursue speed, leading to poor quality of market research. Third, the brand positioning of some enterprises is inconsistent with the actual market situation. When the brand positioning of some enterprises does not conform to the actual market situation, it will lose potential customers. Although at present domestic has many scholars on the concept of brand positioning, brand positioning methods such as question has carried on 
the thorough research, but the emphasis of the different scholars from different research each are not identical, there are many problems need to be solved, such as enterprise on its own brand positioning, how to effectively identify the brand positioning of the validity and efficiency of action. In addition, the current research on how to effectively correct the corporate image in customers' mind lags behind the needs of the current practice development and still needs further in-depth research.

\subsection{The purpose and significance of the study}

Nowadays, enterprises all want to gain competitive advantage through reasonable brand positioning. However, due to the lack of understanding of brand positioning, enterprises often feel at a loss in brand positioning. On the one hand, enterprises do not know what kind of goals they should achieve through brand positioning; on the other hand, enterprises do not know the specific operation steps of brand positioning. Therefore, the research of this paper hopes to help enterprises to check whether the brand image designed by themselves is inconsistent with the image in the mind of customers, and then take further action according to the actual situation.

The study of this paper takes Xiaomi brand as a case. Xiaomi Was founded in 2010, and its business fields include smart phones, smart hardware, smart home ecological chain, etc. Through the research of this paper, I hope to provide an empirical study for the brand positioning of Xiaomi enterprises.

\section{REVIEW OF RELEVANT LITERATURE}

\subsection{The connotation of brand positioning theory}

The concept of positioning was first proposed by Trout in his article Entitled Positioning: Today's Popular imitation Market Games [1]. After that, the theory was further developed and improved based on the theory of STP model, namely market segmentation, market selection and market positioning. The positioning theory became more scientific and more rigorous, which was recognized by management scientists.

Trout and Ries point out that positioning is the activity in which companies try to capture the minds of their customers [2]. The marketing activities of a company should not only aim at the real world, but also aim at the mind of customers, which has become an important battleground in the competition between enterprises.

Wang Xinxin believes that brand positioning essentially occupies a favorable position in the psychology of customers and is the operation of customer psychology, that is, to publicize an idea about the brand to customers, let them understand and accept the idea, and let the idea remain in their minds [3]. Brand positioning is different from product positioning because the primary target of brand positioning is the expected customer rather than the product. The essence of product positioning is to highlight the unique quality of their own products, so that their products have obvious characteristics and can be distinguished from the products of competitors. Brand positioning is to brand the difference of this characteristic in the minds of consumers.

Wang Bo believes that brand is the impression of customers on the logo of a product and the memory of its brand concept [4]. The significance of brand positioning is to transform customers' impression of products into memory of brands, improve customers' brand loyalty, and thus optimize the competitiveness of enterprises in the market. Brand positioning is a way for enterprises to occupy a favorable position in the market competition through a series of planning activities, which can make consumers deeply impressed by the brand.

Wan Shan believes that brand positioning means that an enterprise establishes an appropriate brand image for its target market, makes consumers accept this image and generates brand loyalty [5]. Proper brand positioning can reduce the total cost of enterprise operation and win the competitive advantage for the enterprise. But brand positioning, if there are problems, will also bring losses to the enterprise.

\subsection{The significance of brand positioning for enterprises}

Jiang Siyu pointed out that with the rapid development of China in recent years, people's consumption demands are diversified and personalized, requiring products not only to meet their basic needs, but also to show their own personality [6]. But the product in current domestic competition market is homogenized however, have no distinguishing feature. Therefore, in order to develop in the long run and make their products have different characteristics, enterprises must realize product differentiation through brand positioning as soon as possible. Brand positioning is closely related to advertising strategy. The brand positioning of an enterprise will determine the specific advertising media to be adopted and the features of the product to be highlighted in the advertisement. Therefore, an enterprise must coordinate the relationship between the two, on the one hand, to improve product popularity, and on the other hand, to establish a good social image for the enterprise.

Huo argues that market competition in today's society, the role of marketing is to make the enterprises to further improve its own brand awareness, to better sell their products, and the function of the brand positioning is to attract more customers, encourage consumers to buy the products, improve the brand loyalty of consumers [7]. Therefore, brand positioning plays an indispensable role in the marketing strategy of today's society. Enterprises should find out the key to brand effect in the process of marketing, and further play the role of brand positioning.

Li puts forward that the role of brand positioning in the market marketing strategy is: on the one hand, can be more efficient for the enterprise to sell their products, on the other hand, if the successful brand positioning activities, can use a more efficient way at a higher level to establish business contact with consumers, so as to improve enterprise competitiveness in the market 
environment [8]. In addition, the concept of brand positioning can divide the consumer groups in the current economic market in a more detailed way to improve the effectiveness of marketing work.

Zhao Ping believes that in today's society, competitors' products are characterized by homogeneity and are in a buyer's market [9]. Therefore, enterprises must conduct brand positioning to differentiate their products. In his opinion, brand positioning based on product attributes and benefits is a common development mode in recent years. At this time, brand positioning is equivalent to product positioning, but this brand positioning mode has great risks. He also suggested that brand positioning can be based on the particularity of the brand itself. Brand particularity refers to the brand has a variety of style characteristics, according to these characteristics can be positioned from different angles. Zhao also mentioned that brand positioning can also be based on consumer demand and competition results. Positioning based on consumer demand refers to connecting brands with users and planning for specific groups of consumers. Positioning based on the result of competition means that in brand competition, different products are inevitably used in different occasions. This positioning method based on the result of competition can clarify the market share trend of one's own brand.

\subsection{Methods and strategies for brand positioning}

Li Jinkui puts forward the brand positioning refers to help enterprises in the competition in the market to find a suitable own position, make the enterprise can according to their own resources and external environment condition, create a clear, have their own characteristic meets the needs of consumers to the brand image, to impress consumers to this brand, so that customers have a certain demand, first will first think of the brand of this enterprise [10].

Li-bin Chen and Jiang Lin argue that in order to realize scientific brand positioning, the enterprise must first determine hopes to achieve what goal through brand positioning, the ability to raise consumer's brand loyalty, make consumer brand resonance, let customers to have an emotional connection with the brand, make consumers would prefer the brand products; Secondly, the enterprise should choose the target market of the brand [11]. The enterprise should make clear which market the brand positioning should be in and whether the enterprise should operate a specific small-scale market or choose a large market to establish a distinctive brand image. Enterprises should also clarify the process of brand positioning. In the process of brand positioning, enterprises should first determine the target market and select the main consumer group.

\subsection{Test method for effectiveness of brand positioning}

Zhang Wenlian proposed that effective brand design is a prerequisite for successful brand management. Brand management is a dynamic process of brand system management, while brand design is a relatively static behavior process [12]. In order to make brand design effective, the two should be combined together. Effective strategies for brand design: First, dynamic brand design should be carried out according to the current development status of enterprises and the inner thoughts of customers. Second, according to the characteristics of the enterprise's own products and its own characteristics of the media brand static design, so as to achieve the combination of dynamic and static brand management.

\section{XIAOMI BRAND POSITIONING ANALYSIS}

The company's name is Xiaomi mainly because the Internet industry enterprises prefer the name of "close to the people" and "down-to-earth", which can make consumers see and hear it every day. Xiaomi's product concept is "born for fever", which pursues the ultimate quality and quality. Xiaomi strives for high quality in its manufacturing, and will listen to the opinions of consumers in the online community to optimize its products. Xiaomi also reached a cooperation with Qualcomm, and has the capability of self-development of mobile phone chips.

Xiaomi's goal is to let consumers enjoy the pleasures of technology at a relatively low cost. Xiaomi makes use of the Internet for product development, always pays attention to the ideas of consumers, USES the spirit of the geek to make products, simplifies various links, and strives to enable everyone in the world to enjoy high-quality products that represent the new image of China in the new era.

In a word, the brand positioning of Xiaomi is: in terms of corporate image, Xiaomi pursues innovation, pays attention to product quality, is willing to pay the price for quality progress, and is willing to bear the corresponding social responsibility; In terms of products, Xiaomi is not only engaged in mobile phone business, but also related to mobile phone accessories and consumer goods. It pursues the integration of technology and art and the ultimate cost performance, so that everyone can enjoy the fun of science and technology.

\section{DESIGN AND HYPOTHESIS OF VALIDITY TEST INDEX FOR BRAND POSITIONING}

\subsection{Brand positioning consistency}

The most important factor to test the validity of brand positioning is consistency, that is, whether the image of the brand in consumers' mind is consistent with the image that the brand plans to create in consumers' mind. If the inspection result shows that the expected image of the enterprise is consistent with the image in the mind of consumers, it indicates that the first step of the brand positioning of the enterprise is successful. The enterprise can further build and improve its own image, improve the loyalty of existing consumers, and attract potential consumers to try out its products. If not, the validity of 
brand positioning will be very low, and brand positioning will not bring due benefits to the enterprise.

\subsection{Brand positioning Performance}

The key factor to test the validity of brand positioning is the performance of brand positioning, that is, on the basis of verifying the consistency of brand positioning, to investigate whether consumers are willing to buy the products of enterprises repeatedly. If consumers agree with the brand positioning image of the enterprise, they are willing to continue to buy the products of the enterprise or they are willing to recommend people around to buy the products of the enterprise, then the brand positioning is successful; On the contrary, brand positioning is a failure, and enterprises cannot enjoy the benefits of brand positioning.

\subsection{Brand positioning relevance}

Correlation is an important factor to test the validity of brand positioning, that is, on the basis of verifying the consistency of brand positioning and brand performance, the relationship between brand positioning and brand performance (including brand product repurchase intention, recommendation intention, etc.) is investigated. The aim is to determine the causal relationship between each part of brand positioning image and brand performance. In addition, it can improve its corporate image and further enhance its competitive advantage through the collected information feedback.

\subsection{Theoretical analysis summary and research hypothesis}

When testing the validity of brand positioning, the three evaluation indexes of consistency, performance and relevance are mainly considered.

\subsection{Variable selection}

The title of this paper is "Research on brand positioning validity of Xiaomi". The reason why the three aspects of consistency, performance and relevance are selected for the evaluation index is that these three aspects are effective dimensions affecting brand positioning validity, and the role of these three indicators in brand positioning has been analyzed above.

\subsection{The basic assumptions}

The research object of this paper is Beijing MiUI Technology Co., LTD. The following is the basic hypothesis.

H1: Xiaomi's brand positioning is consistent. It is mainly to verify whether the expected image of enterprises is consistent with the mental image of customers.

$\mathrm{H} 2$ : Xiaomi's brand positioning performance is good. It mainly verifies consumers' repeated purchase intention from the perspective of customers.
H3: Brand positioning of Xiaomi is positively correlated with brand loyalty.

It is mainly to test whether the brand positioning plays a driving role in consumers' relevant behaviors after verifying the brand positioning image consistency, and confirm it through correlation analysis and regression analysis.

\section{DATA ANALYSIS}

\subsection{Questionnaire distribution and data collection}

The content of the questionnaire involves merchants' evaluation of The brand image of Xiaomi. The respondents are mainly consumers who have purchased products related to xiaomi or have some knowledge of the brand, and the respondents are asked to fill in the questionnaire according to their actual situation. The questionnaire was distributed mainly through the network platform and lasted for 3 weeks. In this study, a total of 240 questionnaires were issued, among which 228 were valid and the effective rate of the questionnaires was $95 \%$.

\subsection{Sample analysis}

The following is a preliminary analysis of the questionnaire data, mainly from the two dimensions of gender and age.

\subsubsection{The gender distribution of the sample}

As can be seen from the table below, women account for a relatively large number of subjects, accounting for nearly $58 \%$.

TABLE I. GENDER DISTRIBUTION TABLE OF SAMPLE INTERVIEWEES

\begin{tabular}{|c|r|r|}
\hline Gender & Number of people & \multicolumn{2}{|c|}{ Percentage } \\
\hline Male & 101 & 42.08 \\
\hline Female & 127 & 57.92 \\
\hline
\end{tabular}

As a matter of fact, the majority of online shoppers are women. The marketing channel of Xiaomi is mainly online, so the questionnaire data is in line with the reality.

\subsubsection{Age distribution of respondents}

As can be seen from the table below, the age distribution of Xiaomi consumers is consistent with expectations, and the consumer group is mainly young people.

TABLE II. AGE DISTRIBUTION OF INTERVIEWEES

\begin{tabular}{|c|r|r|}
\hline \multicolumn{1}{|c|}{ Age } & Number of people & \multicolumn{2}{|c|}{ Percentage } \\
\hline $\begin{array}{c}19 \text { and } \\
\text { under }\end{array}$ & 13 & 5.42 \\
\hline $\begin{array}{c}20 \text { to } 29 \\
\text { years old }\end{array}$ & 119 & 54.58 \\
\hline $\begin{array}{c}30 \text { to } 39 \\
\text { years old }\end{array}$ & 74 & 30.83 \\
\hline
\end{tabular}




\begin{tabular}{|c|r|r|}
\hline $\begin{array}{c}40 \text { to } 49 \\
\text { years old }\end{array}$ & 13 & 5.42 \\
\hline $\begin{array}{c}50 \text { to } 59 \\
\text { years old }\end{array}$ & 7 & 2.92 \\
\hline $\begin{array}{c}\text { Age } 60 \\
\text { and above }\end{array}$ & 2 & 0.83 \\
\hline
\end{tabular}

Among the surveyed consumers, those aged 20-29 are the most, followed by those aged 30-39. The least number were aged under 19 and 60 and above.

\section{HYPOTHESIS TESTING}

\subsection{Descriptive statistical analysis}

TABLE III. DESCRIBES THE STATISTICAL SCALE

\begin{tabular}{|l|l|l|l|}
\hline Name & $\begin{array}{l}\text { sample } \\
\text { size }\end{array}$ & Mean & SD \\
\hline Innovative Internet Companies & 228 & 4.146 & 0.696 \\
\hline Technology and art merge & 228 & 3.967 & 0.754 \\
\hline Science and technology of fun & 228 & 4.054 & 0.755 \\
\hline No concern for price & 228 & 4.021 & 0.784 \\
\hline $\begin{array}{l}\text { Technology brings a better life to } \\
\text { the world }\end{array}$ & 228 & 4.05 & 0.791 \\
\hline $\begin{array}{l}\text { Continue to buy Xiaomi branded } \\
\text { products }\end{array}$ & 228 & 4.013 & 0.875 \\
\hline $\begin{array}{l}\text { Pay close attention to the latest } \\
\text { developments of Xiaomi brand }\end{array}$ & 228 & 3.892 & 0.811 \\
\hline Recommend Mi brand products & 228 & 4.042 & 0.862 \\
\hline
\end{tabular}

From the table 3, as we can see that the average score of "innovative Internet" of Xiaomi's brand positioning image is 4.146; the average score of "Integration of Technology and art" was 3.967; the average score of "Technology fun" was 4.054; the average score of "heartwarming price kindness" is 4.021; ' Technology brings a better Life to the world' scored an average of 4.05. Since the score of each question is set from 1 to 5 ( 1 is the lowest score and 5 is the highest score), it can be considered that the expected image of Xiaomi's brand positioning is basically consistent with its image in the minds of consumers, with good consistency. That is to say, hypothesis 1 is supported.

The average score of "continue to buy Miui brand products" was 4.013. The average score of "paying attention to the latest developments of Xiaomi brand" is 3.892. The average score of "Recommend Mi brand products" was 4.042. This can show that Xiaomi's brand positioning has a good performance. Consumers accept and recognize the image of Xiaomi's brand positioning, so they have a good intention of repeated purchase and are willing to buy related products of Xiaomi brand. It is preliminarily believed that hypothesis 2 is supported.

\subsection{Correlation analysis}

Correlation analysis is a statistical analysis of the observed values of relevant things with some reasonable indicators. Here, we believe that brand loyalty can best represent brand performance.

\section{TABLE IV. CORRELATION ANALYSIS}

\begin{tabular}{lccc}
\hline \multicolumn{4}{c}{ brand positioning } \\
\hline \multirow{4}{*}{ Pearson correlation } & 1 & $.672^{* *}$ \\
brand loyalty & Sig. & & .000 \\
& $\mathrm{~N}$ & 228 & 228 \\
\hline
\end{tabular}

It can be seen from the above table that brand loyalty is significantly positively correlated with Xiaomi brand positioning at the level of 0.01 , with a correlation coefficient of 0.672 , indicating a close correlation. Thus, Hypothesis 3 is supported.

\section{3 analysis of regression}

Regression analysis is a commonly used statistical method of SPSS data, which is mainly used to explore the relationship between data. It is a model to explore the relationship between dependent variable $\mathrm{Y}$ and independent variable $\mathrm{X}$.

The following table can shows that xiaomi's brand positioning image has a very close positive influence on its brand loyalty. The coefficient of regression equation is 0.672 .

TABLE V. REGRESSION EQUATION

\begin{tabular}{lrrrrr}
\hline \multicolumn{7}{c}{$\begin{array}{c}\text { Unstandardized } \\
\text { Coefficients }\end{array}$} & \multicolumn{2}{l}{$\begin{array}{l}\text { Standardized } \\
\text { Coefficients }\end{array}$} \\
model & $\mathrm{B}$ & $\mathrm{SE}$ & & $\mathrm{t}$ & \multicolumn{1}{c}{ Sig. } \\
\hline 1 (constant) & $-4.586 \mathrm{E}-16$ & .048 & & .000 & 1.000 \\
$\begin{array}{l}\text { brand } \\
\text { positioning }\end{array}$ & .672 & .048 & .672 & 14.006 & .000 \\
\hline
\end{tabular}

a. Dependent variable: Brand loyalty.

\section{4 research results}

After the above analysis, all hypothesis testing has been completed in this paper. The research hypothesis verification situation is shown in the following table:

TABLE VI. HYPOTHESIS VERIFICATION RESULTS

\begin{tabular}{llc}
\hline hypothesis & content & $\begin{array}{c}\text { research } \\
\text { conclusions }\end{array}$ \\
\hline $\mathrm{H} 1$ & $\begin{array}{l}\text { brand positioning is } \\
\text { consistent } \\
\text { brand positioning } \\
\text { performance is good }\end{array}$ & support \\
$\mathrm{H} 2$ & $\begin{array}{l}\text { Brand positioning is } \\
\text { positively correlated } \\
\text { with brand loyalty }\end{array}$ & support \\
\hline
\end{tabular}




\section{RESEARCH CONCLUSION AND COUNTERMEASURE SUGGESTION}

\subsection{The results of the study}

From the survey, we find that The brand positioning validity of Xiaomi is relatively high. Consumers agree that Xiaomi is an innovative Internet company, that its products integrate technology and art, and that they can enjoy fun in the process of using Xiaomi products. At the same time, consumers also agree that the products of Miui brand are of generous price, touching people's hearts, and have extremely high cost performance. We are bringing a better life for domestic and foreign consumers with technology.

Secondly, we can find that Xiaomi brand positioning has a good performance. As can be seen from the above analysis, on the basis of purchasing Xiaomi products in the past, consumers are willing to buy related products of this brand repeatedly in the future, continue to pay attention to the new trends of this brand, and recommend Xiaomi to people around.

Through correlation analysis and regression analysis, we can see that Xiaomi brand positioning is positively correlated with brand loyalty. Brand loyalty is reflected by consumers' repeated purchase intention, and consumers' repeated purchase intention determines brand performance to a large extent. Therefore, we can think that the brand positioning of Xiaomi has a significant positive correlation with its brand performance, and that the successful positioning of Xiaomi's brand is an important reason for its remarkable performance.

\subsection{Countermeasures and Suggestions}

Based on the findings of this study, it can be found that the brand positioning validity of Xiaomi is generally effective, but there are still some areas that can be further improved. The author puts forward the following Suggestions:

First, Xiaomi has positioned itself as an innovative Internet company. Although consumers agree with this image, the survey scores show that Xiaomi can do better in this regard. For Xiaomi to truly transform itself from a hardware company to an Internet company, it must look to IOT (Internet of Things) for opportunities.

Second, xiaomi's products have always been known for their "cost performance", that is, "touching people's hearts and generous prices". The data obtained from the survey also confirmed this point once again. However, due to the fierce competition in the domestic mobile phone market, the advantage of cost-performance becomes smaller and smaller for Xiaomi, because low price can only gain competitive advantage in a short period of time, but cannot always rely on price-performance to maintain customer stickiness in the long run. Therefore, Xiaomi should step up its transformation and wean itself off its reliance on low-end products.

Third, in the survey, it can be found that consumers are not very enthusiastic about whether they are willing to pay continuous attention to the latest developments of Xiaomi brand. This shows that Xiaomi should build and maintain a good relationship with consumers. Xiaomi can make full use of its online community to collect consumer opinions on its products, services and other aspects as a basis for improving its work. At the same time, it should maintain real-time communication with consumers to keep a good relationship with consumers.

\section{REFERENCES}

1. Trout, J. Positioning is a game people play in today's me - too market place [J]. Industrial Marketing, 1969(1):51-55.

2. Trout, J., \& Ries, A. Positioning: The Battle for Your Mind [J]. Ohio: McGraw Hill, 1972.

3. Xin-Xin Wang. Brand positioning is not product positioning[J]. Enterprise Studies, 2007(03): 50-52.

4. Bo Wang. On the importance of brand positioning in marketing strategy[J]. South wind, 2016(32): 127.

5. Shan Wan. Brand positioning Error and countermeasures $[\mathrm{J}]$. Cooperative economy and technology, 2018(19):92-94.

6. Siyu Jiang. The realization and analysis of enterprise brand positioning advertising strategy[J]. Theory of China, 2017(14): 4-5.

7. Erman Huo. The importance of brand positioning in marketing strategy[J]. modern marketing, 2018(12): 59.

8. Yan Li. On the importance of brand positioning in marketing strategy[J]. Market Modernization, 2018 (21): 56-57.

9. Ping Zhao. Discussion on the position of brand positioning in marketing strategy[J]. the reform and opening-up policy, 2018 (20): 6-8.

10. Jinkui Li. Methods and mistakes of brand positioning[J]. Chinese advertisement, 2012(6): 158-160.

11. Libin Chen, Lin Jiang. Get rid of the misunderstanding of brand positioning[J]. marketing planning, 2013: 45-46.

12. Wenlian Zhang. Research on the effectiveness strategy of brand design[J]. Journal of Tonghua Teachers College, 2014(6): 132-134. 